\title{
Correction to: Compound heterozygous variants including a novel copy number variation in a child with atypical ataxia-telangiectasia: a case report
}

Hoo Young Lee ${ }^{1,2,3,4}$, Dae-Hyun Jang ${ }^{5^{*}}$, Jae-Won Kim5 ${ }^{5}$ Dong-Woo Lee ${ }^{5}$, Ja-Hyun Jang ${ }^{6}$ and Joungsu Joo ${ }^{7}$

\section{Correction to: BMC Med Genomics 14, 204 (2021)} https://doi.org/10.1186/s12920-021-01053-3

Following publication of the original article [1], the authors reported an error in Fig. 2.

Figure 2 was replaced as the authors identified an error in part $\mathrm{C}$ that was introduced during the peer review process. This error may have affected the interpretation of the results, and therefore, the figure was replaced with the earlier correct version. The original article [1] has been corrected.

\section{(See figure on next page.)}

Figure 2 a Chromatograms of ATM sequence in the proband (top), the patient's father (middle), and the patient's mother (bottom) showing an SNV of c.742C > T (p.Arg248Ter) from the father. $\mathbf{b}$ Analysis of the next-generation sequencing data using VisCap. c SNP array analysis of the chromosome from the proband (top), the patient's mother (middle), and the patient's father (bottom) showing a novel CNV by the deletion of exons 24-40 from the mother. SNV single-nucleotide variation, SNP single-nucleotide polymorphism, CNV copy number variation

The original article can be found online at https://doi.org/10.1186/s12920021-01053-3.

*Correspondence: dhjangmd@naver.com

${ }^{5}$ Department of Rehabilitation Medicine, Incheon St. Mary's Hospital,

College of Medicine, The Catholic University of Korea, 56, Dongsu-ro,

Bupyeong-gu, Incheon 21431, Republic of Korea

Full list of author information is available at the end of the article

(c) The Author(s) 2021. Open Access This article is licensed under a Creative Commons Attribution 4.0 International License, which permits use, sharing, adaptation, distribution and reproduction in any medium or format, as long as you give appropriate credit to the original author(s) and the source, provide a link to the Creative Commons licence, and indicate if changes were made. The images or other third party material in this article are included in the article's Creative Commons licence, unless indicated otherwise in a credit line to the material. If material is not included in the article's Creative Commons licence and your intended use is not permitted by statutory regulation or exceeds the permitted use, you will need to obtain permission directly from the copyright holder. To view a copy of this licence, visit http://creativecommons.org/licenses/by/4.0/. The Creative Commons Public Domain Dedication waiver (http://creativecommons.org/publicdomain/zero/1.0/) applies to the data made available in this article, unless otherwise stated in a credit line to the data. 

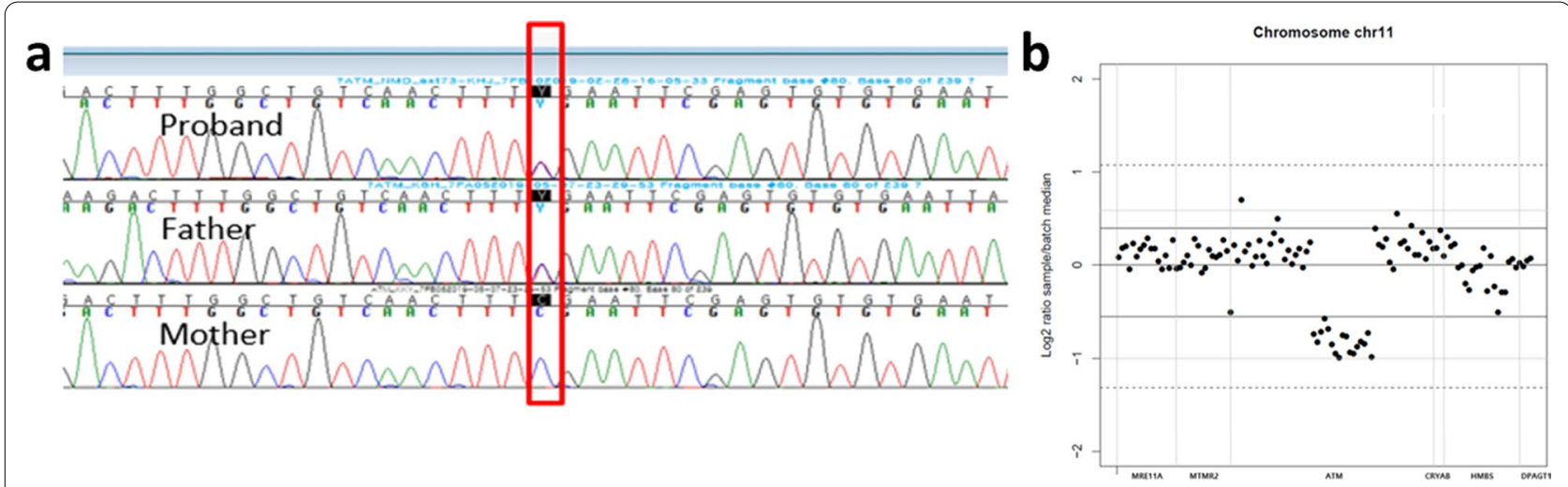

C
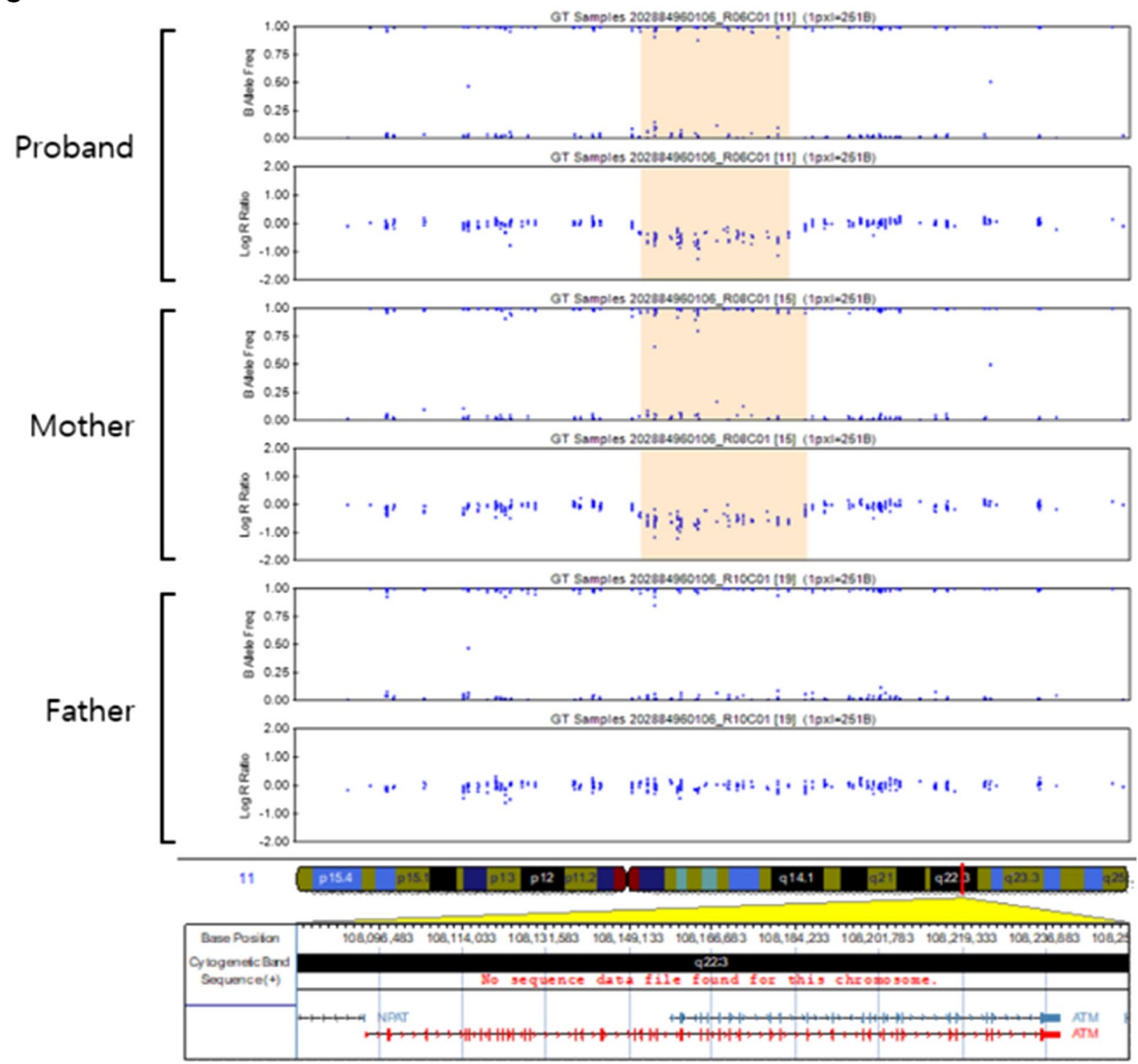

Figure 2 (See legend on previous page.) 


\section{Author details}

${ }^{1}$ TBI Rehabilitation Center, National Traffic Injury Rehabilitation Hospital, Gyeonggi-do, Republic of Korea. ${ }^{2}$ Department of Rehabilitation Medicine, Seoul National University Hospital, Seoul, Republic of Korea. ${ }^{3}$ Department of Medicine, Yonsei University College of Medicine, Seoul, Republic of Korea. ${ }^{4}$ National Traffic Injury Rehabilitation Research Institute, National Traffic Injury Rehabilitation Hospital, Yangpyeong, Korea. ${ }^{5}$ Department of Rehabilitation Medicine, Incheon St. Mary's Hospital, College of Medicine, The Catholic University of Korea, 56, Dongsu-ro, Bupyeong-gu, Incheon 21431, Republic of Korea. ${ }^{6}$ Department of Laboratory Medicine and Genetics, Samsung Medical Center, Seoul, Korea. ${ }^{7}$ EONE-DIAGNOMICS Genome Center, Incheon, Republic of Korea.

Published online: 20 September 2021

\section{Reference}

1. Lee HY, Jang DH, Kim JW, et al. Compound heterozygous variants including a novel copy number variation in a child with atypical ataxia-telangiectasia: a case report. BMC Med Genomics. 2021;14:204. https://doi.org/ 10.1186/s12920-021-01053-3.

\section{Publisher's Note}

Springer Nature remains neutral with regard to jurisdictional claims in published maps and institutional affiliations. 